\title{
The Performance of Mixture Refrigerant R134a/R152a in a Novel Gas Engine-Driven Heat Pump System
}

\author{
Xi Wu${ }^{1}$, Zhao Yang ${ }^{1 *}$, Huanwei Liu ${ }^{1}$, Zhongjie Huan ${ }^{2}$, and \\ WenbinWang 1
}

\begin{abstract}
${ }^{1}$ School of Mechanical Engineering, Key Laboratory of Efficient Utilization of Low and Medium Grade Energy, MoE, Tianjin University, Tianjin, China

${ }^{2}$ Department of Mechanical Engineering, Pretoria Campus, Tshwane University of Technology, Pretoria, South Africa

*Address correspondence to Zhao Yang, School of Mechanical Engineering, Tianjin University, 92 Weijin Road, Nankai District, Tianjin,300072, China. E-mail: zhaoyang@tju.edu.cn
\end{abstract}

\begin{abstract}
In the present article, a novel gas engine-driven heat pump (GEHP) which could independently provide heating, cooling, and hot water for the buildings with its autonomous power supply system was presented, and the cooling performance characteristics of GEHP using mixture refrigerant R134a/R152a were investigated experimentally. The thermophysical properties and flammability of this proposed mixture refrigerant were analyzed and experimented to approve that it could be used safely in GEHP. The experimental results indicated that the cooling capacity, waste heat recovered from cylinder jacket and exhaust gas, gas engine energy consumption, and compressor power increased with the increase of the gas engine speeds and evaporator water inlet flow rate, but changed in a small range with the increase of the evaporator water inlet temperature except cooling capacity. The generator power remained about $4.90 \mathrm{~kW}$ in different operating conditions. Furthermore, the coefficient of performance (COP) and the primary energy ratio (PER) of GEHP also increased with the increase of the evaporator water inlet flow rate and temperature, but decreased with the increase of gas engine speeds. Finally, maximum COP and PER with mixture refrigerant R134a/R152a has been estimated with 8.88 and 1.69 in the aforementioned conditions.
\end{abstract}

Keywords: Gas engine-driven heat pump; Operating characteristics; R134a/R152a; Flammability limits; Primary energy ratio

\section{INTRODUCTION}

A gas engine-driven heat pump (GEHP) (Yang, Zhao, and Li 2005; Zhang, Lu, and Li 2005; Li, Zhang, and Liang 2007; Hepbaslia et al. 2009; Xu and Yang 2009) is composed of a heat pump system with an open compressor driven by a gas fueled internal combustion engine. The GEHP has been considered as a preferable choice in the heating and air-conditioning scheme in winter and summer (Yang, Zhang, and Zhao 2003). Compared with the electric-driven heat pump (EHP), the GEHP has two distinguished advantages: (1) the ability to recover the gas engine waste heat from cylinder jacket and exhaust gas 
and (2) easy modulation of gas engine speed to meet the cooling/heating loads. Therefore, the GEHP has been widely focused on the heating and air-conditioning system ( $\mathrm{Li}$ et al. 2005; Lian et al. 2005; Lazzarin and Noro 2006). Cabello, Navarro, and Torrella (2005) proposed a steady state model of a vapor compression system using theoretical and empirical correlations. They validated the system modeling using experimental data obtained in a wide range of operating conditions. Gungor, Erbay, and Hepbasli (2011a, 2011b) have performed a pilot scale gas engine driven heat pump (GEHP) drying system, and the performance of the drying process was also analyzed for three different medicinal and aromatic plants from the exergoeconomic point of view. In the Choi and Kim's study (2003), the performance of an air conditioner with two indoor units was measured by varying indoor loads, expansion valves opening, and compressor speed. Based upon the experimental results, the operating characteristics and capacity modulation of the air conditioner were discussed. Petel and Henderson (1998) compared the performance of a gas enginedriven cooling system with R22 and R134a. Both systems were monitored to determine the energy consumption, delivered cooling capacity, coefficient of performance (COP), as well as hours and modes of operation. Yang, Zhao, and Fang (2007) has established model and dynamic control simulation of unitary gas engine heat pump, based on the eight dynamic models of the gas engine heat pump (GEHP) system, an intelligent control simulation was presented to research the dynamic characteristics of the system in the operation. The model was very effective in analyzing the effects of the control system, and the steady state accuracy of the intelligent control scheme was higher than that of the fuzzy controller. The main applications of GEHPs are for space and water heating/cooling purposes. However, they can be integrated to industrial applications, especially in drying processes, which has been widely used in different industrial sectors because of their energy-intensive nature (Oktay 2003; Yang, Zhao, and Li 2005). Elgendy and Schmit (2010) and Elgendy et al. (2010) have studied the heating/cooling performance of gas engine driven air to water heat pump with mixture refrigerant R410A, several factors (gas engine speeds, evaporator water inlet temperature and so on) on the performance of GEHP system were performed. Sun, Wang, and Sun (2004) and Sun (2007) proposed a combined heat and cold system driven by a gas industrial engine, which primary energy rate of was about 1.90, and the comparative saving of primary energy demand of the combined system reached $40.9 \%$ compared to conventional separate system of cold and heat supply (direct fired absorption chiller for cooling and gas boiler for heating).

In this present study, a novel air-water GEHP which could independently provide heating, cooling, and hot water for the buildings with its autonomous power supply system was developed. Compared with the common heat pump, the novel GEHP holds two main advantages: first of all, it can be run without the support of power net and avoiding the effect of power outage; secondly, waste heat recovered from the gas engine cylinder jacket and exhaust gas can be used efficiently, thus it has a higher primary energy ratio (PER) than the general electrical heat pumps. Therefore, the purpose of this study is to experimentally investigate the cooling performance characteristics of GEHP. Furthermore, an alternative mixture refrigerant R134a/R152a with lower GWP and zero ODP was utilized to the GEHP, and the thermophysical properties and flammability of this mixture refrigerant R134a/R152a were analyzed too. Based upon the experimental data, the effects of gas engine speeds, evaporator water inlet flow rate and evaporator water inlet temperature on the cooling performance characteristics (cooling capacity, waste heat, generator power, gas engine energy consumption, compressor power, COP, and PER) of GEHP using mixture refrigerant R134a/R152a have been discussed. 


\section{EXPERIMENTAL APPARATUS}

\section{Thermophysical Properties of R134a/R152a}

In the present study, a mixture refrigerant R134a/R152a (40/60 wt\%) is proposed as the working fluid for the GEHP, which is selected according to the thermophysical properties (smaller temperature glide, suitable pressure, and better cycling performance) and safety property (lower flammability), the thermophysical properties of this proposed mixture refrigerant are presented in Table 1 based on the theoretically calculating and experimental testing. It can be seen that the mixture refrigerant has zero $O D P$ and lower GWP than R134a as well as R22.

Figure 1 shows a cluster of vapor pressure curves of mixture refrigerant R134a/ $\mathrm{R} 152 \mathrm{a}$ and R134a. It can be seen from the figure that the vapor pressure curve of pure refrigerant R134a is near that of mixture refrigerant R134a/R152a. Figure 2 shows that the temperature glide of mixture refrigerant $\mathrm{R} 134 \mathrm{a} / \mathrm{R} 152 \mathrm{a}$ is no more than $0.1{ }^{\circ} \mathrm{C}$. Therefore, the mixture refrigerant R134a/R152a can be charged into the GEHP from the aspect of vapor pressure and temperature glide.

The explosive limits of the mixture refrigerant R134a/R152a have been experimented for the flammability of R152a before its utilization to the GEHP. According to National Standard GB/T12474-90 (1990), an experimental appliance (Yang, Liu, and Zhao 2004) used to measure the explosive limits of flammable refrigerants in air was designed, as seen in Figure 3. The vessel is a vertical glass cylinder which is $1450 \pm 50 \mathrm{~mm}$ in height and $60 \pm 5 \mathrm{~mm}$ in inner diameter including ignition device, churn-dasher, vacuum

Table 1 Basic Parameters of R134a/R152a

\begin{tabular}{lcccccc}
\hline Refrigerant & ODP & GWP & $\begin{array}{c}\text { Molar mass/ } \\
\mathrm{g} / \mathrm{mol}\end{array}$ & $\begin{array}{c}\text { Critical } \\
\text { temperature } /{ }^{\circ} \mathrm{C}\end{array}$ & $\begin{array}{c}\text { Critical } \\
\text { pressure } / \mathrm{MPa}\end{array}$ & $\begin{array}{c}\text { Critical } \\
\text { density } / \mathrm{Kg} / \mathrm{m}^{3}\end{array}$ \\
\hline R134a/R152a & 0 & 907.6 & 83.78 & 107.14 & 4.256 & 439.26 \\
\hline
\end{tabular}

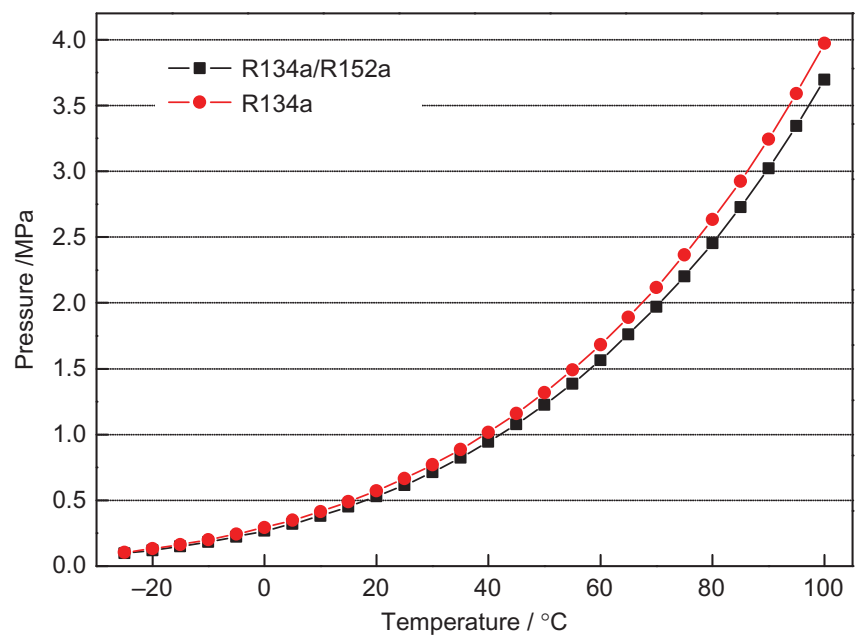

Figure 1 Saturated vapor pressure comprehensive graph of R134a/R152a (color figure available online). 


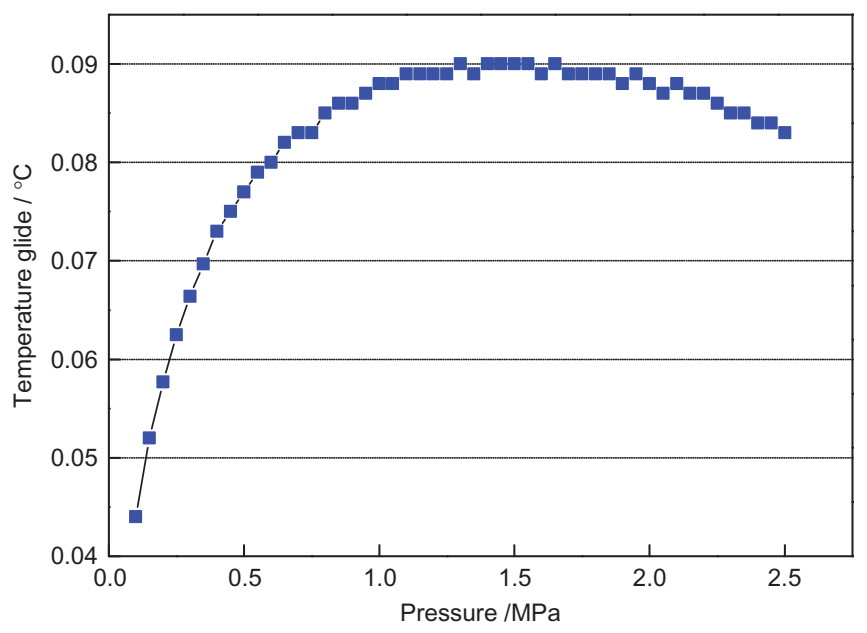

Figure 2 Theoretical temperature glides of R134a/R152a (color figure available online).

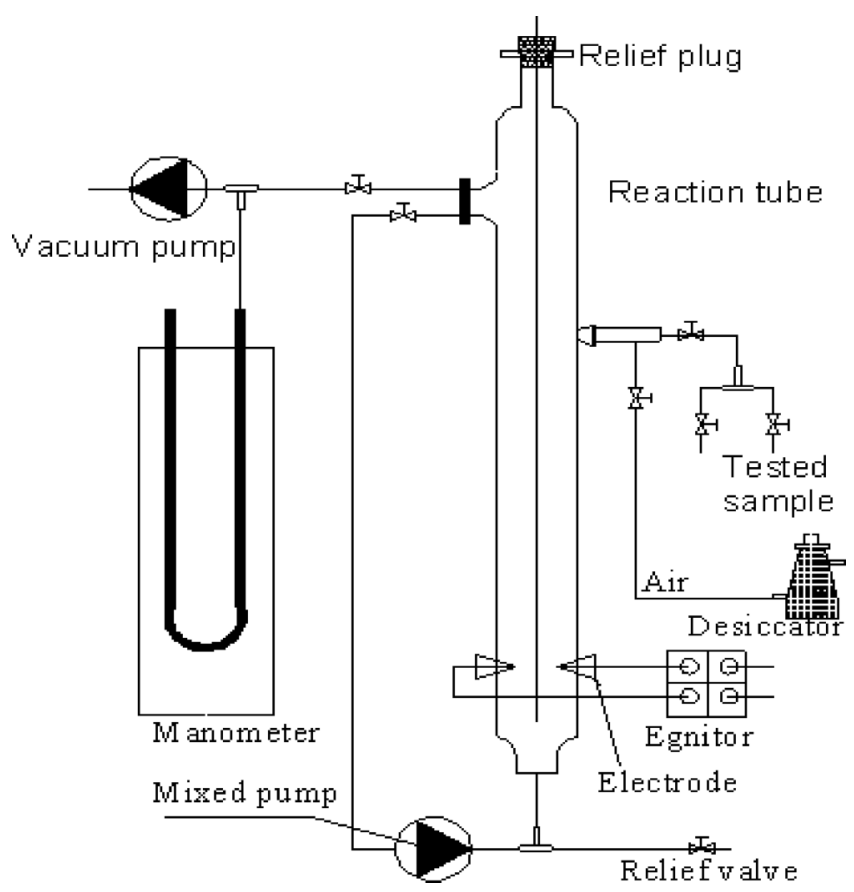

Figure 3 Scheme of gas explosion limits test.

pump, manometer, relief valve, and so on. The experimental temperature is $290-295 \mathrm{~K}$ and pressure is about $101.325 \mathrm{KPa}$ (one atmosphere pressure, $760 \mathrm{~mm} \mathrm{Hg}$ ). The experimental explosive limits including LFL (Lower flammability limits) and UFL (Upper flammability limits) and range of mixture refrigerant R134a/R152a are shown in Figure 4. 


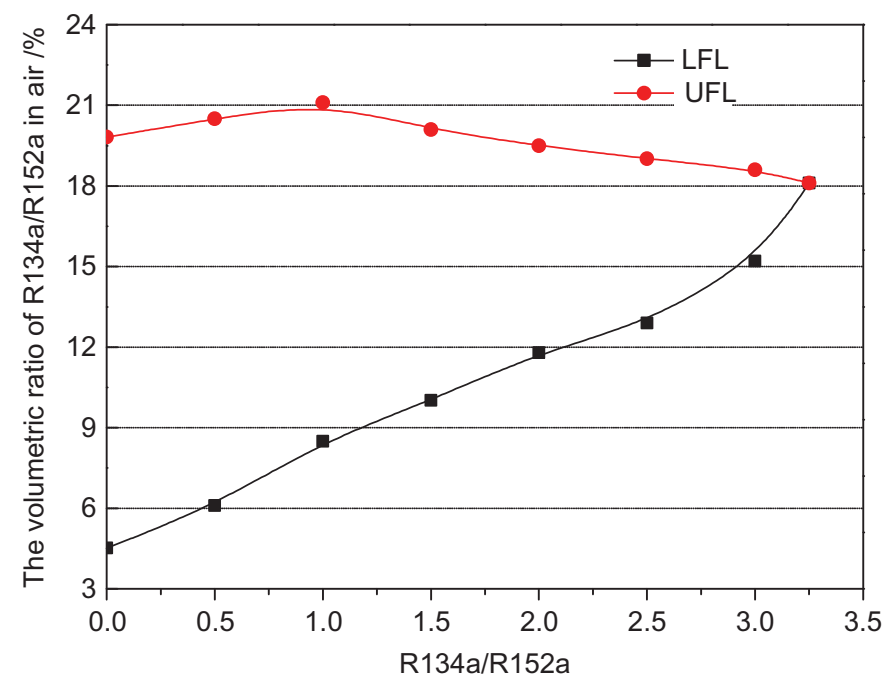

Figure 4 Explosion limits of mixture refrigerant R134a/R152a (color figure available online).

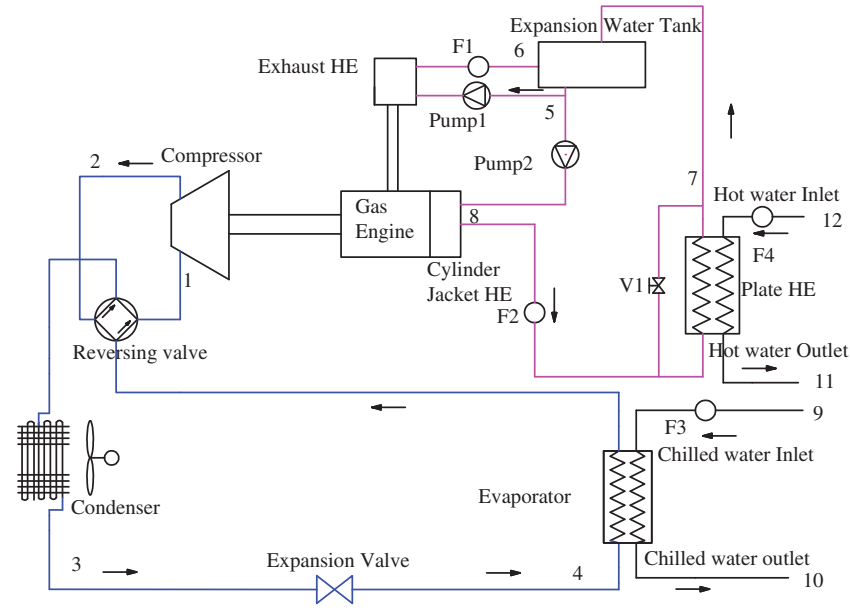

Figure 5 Schematic diagram of gas engine-driven heat pump system (color figure available online).

\section{System Description}

Figure 5 presents a novel air to water type GEHP, which can work as either a heat pump or a chiller. The GEHP includes four parts, which are gas engine, heat pump system, waste heat recovery apparatus, and power generation system. The heat pump system itself includes an open type compressor connected to the gas engine directly by a belt, which is different from the ordinary EHP. In the GEHP, cylinder jacket heat exchanger and exhaust heat exchanger are adopted to recover the gas engine waste heat, which could be used for enhancing the heating capacity of the GEHP in two ways: (1) in heating mode, the waste heat improves the water temperature recycled from the buildings and (2) in cooling mode, the waste heat can provide the hot water to the 
buildings through the plate heat exchanger. The power generation system includes generator and a set of battery packs which can provide the power supply to the GEHP. The generator is directly driven by gas engine and the output power is changed by regulating the gas engine speeds. The generator can provide the power to the fans and water pumps on the operating condition and store the superfluous power in the battery packs. Therefore, the GEHP can independently realize the energy supply without other electric supply.

From Figure 5, we can see that the experimental apparatus includes four circulations, that is, mixture refrigerant circulation, gas engine coolant circulation, chilled water circulation, and the hot water circulation.

(1) Mixture refrigerant circulation is comprised of an open compressor, an electronic expansion valve, an evaporator and a condenser followed by a receiver, a filterdriver and a sight glass. Mixture refrigerant (R134a/R152a), absorbing heat in the evaporator, flows to the compressor through compressor inlet (state point 1) and the reversing valve, the compressor increases the pressure of the mixture refrigerant and delivers superheated vapor (state point 2) to the condenser (state point 3) through an oil separator, then, mass flow rate of the condensed mixture refrigerant is measured before passing through the electronic expansion valve. Finally, the mixture refrigerant returns back to the evaporator (state point 4 ).

(2) Gas engine coolant circulation includes two parts: the cylinder jacket coolant circulation and exhaust gas coolant circulation. The coolant discharged from the coolant pump 1 (state point 5) is heated by the heat released from the exhaust gas. The heated coolant (state point 6) comes back to the expansion water tank after its volume flow rate is measured using volume flow meter (F1). At the same time, the coolant discharged from the coolant pump 2 (state point 5) is further heated by the cylinder jacket waste heat. The heated coolant (state point 8) which volume flow rate is measured using volume flow meter (F2) passes through a shortcut via a thermostat valve (V1) paralleled the plate heat exchanger when the coolant temperature is low (lower than $50^{\circ} \mathrm{C}$ ) at gas engine start-up, as the coolant temperature increases (higher than $50^{\circ} \mathrm{C}$ ), the coolant flows into the plate heat exchanger to dissipate heat to the hot water and then comes back to the expansion tank (state point 7).

(3) Chilled water circulation. Chilled water coming out from indoor unit (state point 9) is pumped into the evaporator where heat transfers from the chilled water to mixture refrigerant, then, the chilled water returns back to the indoor unit (state point 10) after its volume flow rate is measured using volume flow meter (F3).

(4) Hot water circulation. Hot water discharged from water tank (state point 12) is pumped into the plate heat exchanger, then, the heated hot water returns back to the water tank (state point 11) after its volume flow rate is measured using volume flow meter (F4).

Copper-constantan thermocouples with the accuracy of $\pm 0.5^{\circ} \mathrm{C}$ are used to measure operating temperatures while digital pressure gauges are used to record the operating pressures. The mass flow rate of refrigerant is measured using DMF-1-2-A flow meter while the gas engine coolant, chilled and hot water flow rates are measured using LWY-4-25 pipeline turbine flow meter with the accuracy of $\pm 0.5 \%$. All the measured data are recorded using the Germany Siemens Programmable Logic Controller S7-200 and displayed using Zutai software. 


\section{THEORETICAL DATA COMPUTATION}

The measuring point locations of temperature, pressure, and flow rate are shown in Figure 5. The cooling performance characteristics of GEHP with mixture refrigerant $\mathrm{R} 134 \mathrm{a} / \mathrm{R} 152 \mathrm{a}$ are calculated as follows:

Energy and mass balances are carried out for the main components of GEHP to compute their loads. The energy consumption of gas engine can be written as follows

$$
Q_{\mathrm{gas}}=M_{\mathrm{gas}} L H V
$$

The cooling capacity of GEHP is calculated as follows

$$
Q_{e}=M_{\mathrm{ref}}\left(h_{1}-h_{4}\right)
$$

The cooling capacity also can be calculated by applying energy balance equation for the evaporator as follows

$$
Q_{e}=M_{3 w} C_{\mathrm{pw}}\left(T_{9}-T_{10}\right)
$$

The waste heat includes two parts: the cylinder jacket waste heat and exhaust gas waste heat. Therefore, the waste heat recovered from cylinder jacket and exhaust gas is calculated as follows, respectively.

$$
\begin{gathered}
Q_{\mathrm{cj}}=M_{2 w} C_{\mathrm{pw}}\left(T_{8}-T_{5}\right) \\
Q_{\mathrm{exh}}=M_{1 w} C_{\mathrm{pw}}\left(T_{6}-T_{5}\right)
\end{gathered}
$$

The variation of $M_{2 \mathrm{w}}$ and $M_{1 \mathrm{w}}$ with gas engine speeds is depicted in the Figure 6.

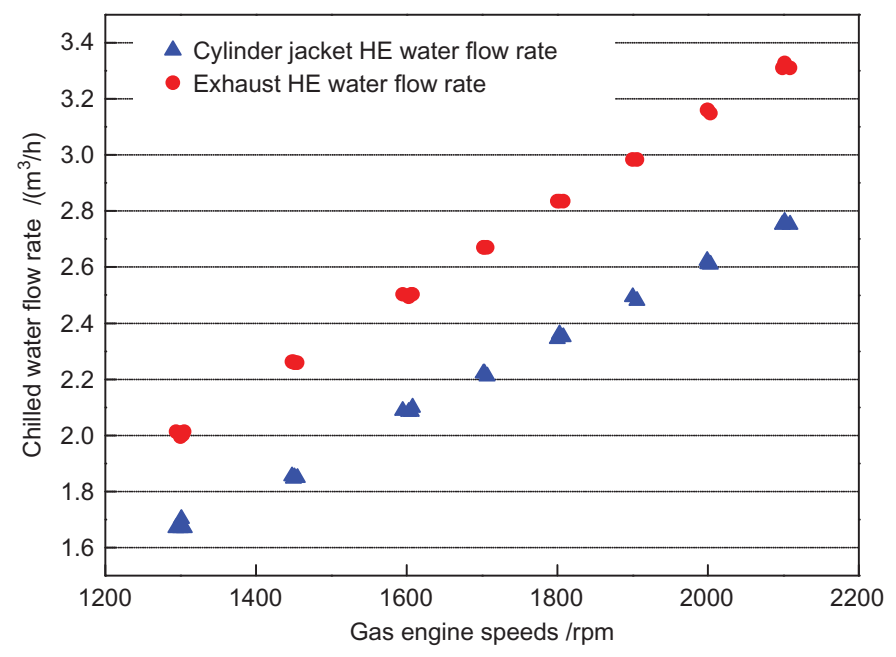

Figure 6 Variation of cooling water inlet flow rate with engine speeds (color figure available online). 
The GEHP also includes a generator and a set of battery packs which can provide the power supply to the GEHP. As a result, the GEHP realizes the autonomous power supply. The output power of generator is calculated as follows

$$
W_{\text {gen }}=U I
$$

Then, compressor power $\left(P_{\text {com }}\right)$ is described as

$$
P_{\text {com }}=M_{\text {ref }}\left(h_{2}-h_{1}\right)
$$

COP and PER are main evaluation parameters of the characteristics of the GEHP, they are calculated as follows

$$
\begin{gathered}
C O P=\frac{Q_{e}+Q_{\mathrm{cj}}+Q_{\mathrm{exh}}}{P_{\mathrm{com}}} \\
P E R=\frac{Q_{\mathrm{all}}}{Q_{\mathrm{gas}}}=\frac{Q_{e}+Q_{\mathrm{cj}}+Q_{\mathrm{exh}}+W_{\mathrm{gen}}}{Q_{\mathrm{gas}}}
\end{gathered}
$$

\section{RESULTS AND DISCUSSIONS}

The water temperature between $6^{\circ} \mathrm{C}$ and $12^{\circ} \mathrm{C}$ was recommended for summer airconditioning chiller units. Hence, the evaporator water mass flow rate was adjusted to obtain water outlet temperature. At the same time, the GEHP system can change the gas engine speeds easily to achieve different cooling capacity.

\section{Performance of GEHP Under Different Gas Engine Speeds}

In regard to the EHP, which cooling/heating capacity adjustment can be achieved by frequency converter, as for the GEHP, the capacity adjustment can be regulated by altering the gas engine speeds, which is one of advantages of the GEHP. Figure 7 presents the cooling capacity, waste heat, and generator power vary with the gas engine speeds under the conditions of ambient temperature $32.3^{\circ} \mathrm{C}$ and evaporator water inlet flow rate $5.43 \mathrm{~m}^{3} / \mathrm{h}$. Cooling capacity, waste heat are increased as the increase of gas engine speeds, it because that the mixture refrigerant mass flow rate and the heat transfer coefficient of mixture refrigerant increase as the gas engine speeds increase from 1300 to $1900 \mathrm{rpm}$. Therefore, compressor power and gas engine energy consumption are also increased as seen from Figure 8 . The generator power is nearly unchanged, it is because that the generator power is only related to the generator speeds. The output current of generator remains about 160 A under the condition that the generator speeds exceed $3000 \mathrm{rpm}$. So, the generator power is approximately $4.92 \mathrm{~kW}$ which meets the electricity requirements of the GEHP. What is more, as seen in Figure 7, the waste heat accounts for more than $80 \%$ of cooling capacity of GEHP, thus the waste heat has contributed to the improvement of the GEHP's performance.

Figure 9 shows that COP and PER vary with gas engine speeds. Although the cooling capacity and waste heat increase $27.3 \%$ and $36.8 \%$ from $1300 \mathrm{rpm}$ to $1900 \mathrm{rpm}$ respectively, the gas engine energy consumption and compressor power also increase $41.6 \%$ and $53.1 \%$ respectively. Thus, COP and PER decrease as the result of increasing the gas engine 


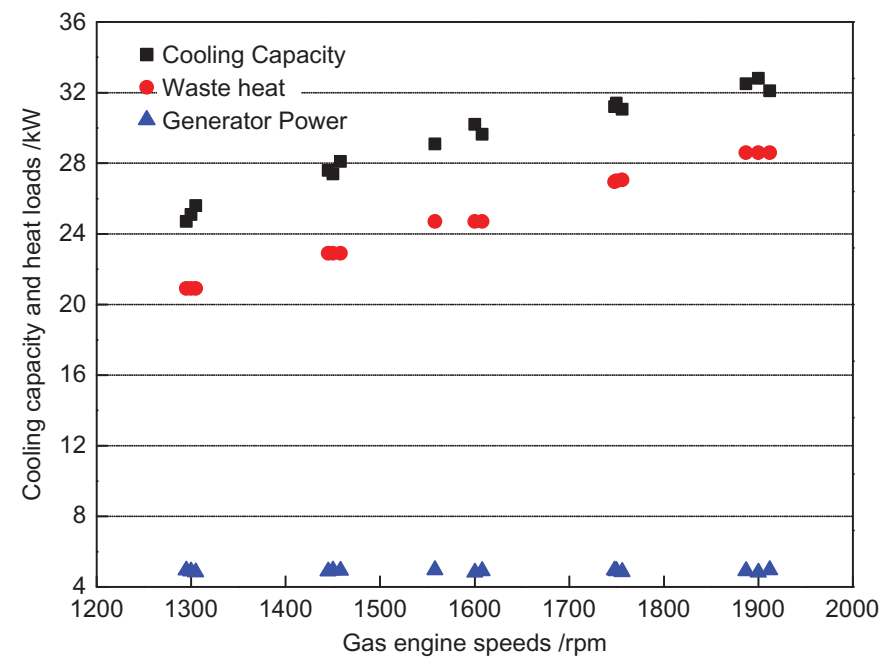

Figure 7 Variation of cooling capacity, waste heat and generator power versus gas engine speeds (color figure available online).

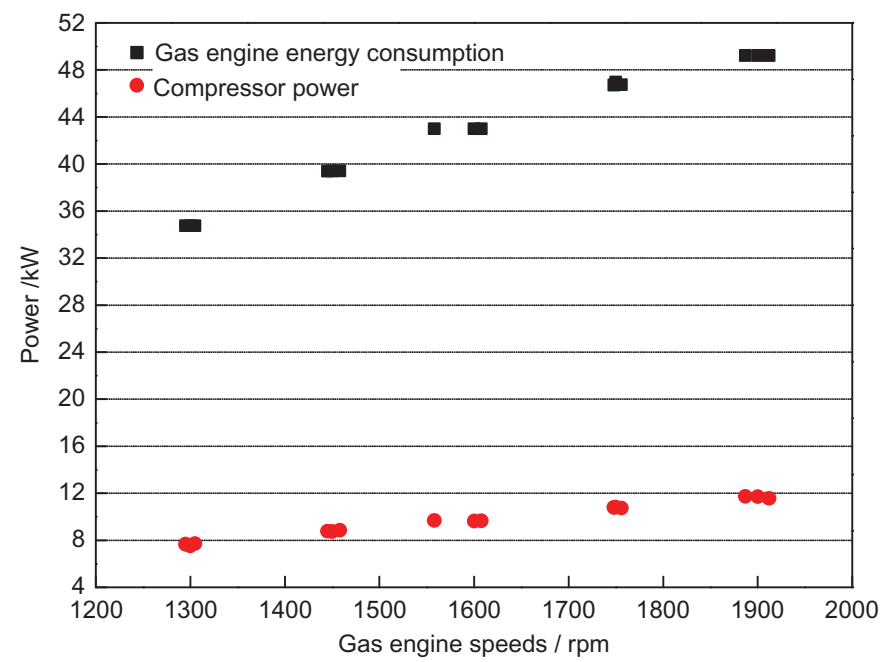

Figure 8 Variation of system power versus gas engine speeds (color figure available online).

speeds. Taking into account of the gas engine dynamic and economic property, the gas engine maintains lower speed to achieve the higher COP and PER.

\section{Performance of GEHP Under Different Evaporator Water Inlet Flow Rate}

Figure 10 presents variation of the cooling capacity, waste heat and generator power with evaporator water inlet flow rate under the conditions of ambient temperature $32.3^{\circ} \mathrm{C}$ and gas engine speed $1600 \mathrm{rpm}$. The coefficient of heat transfer of chilled water increases 


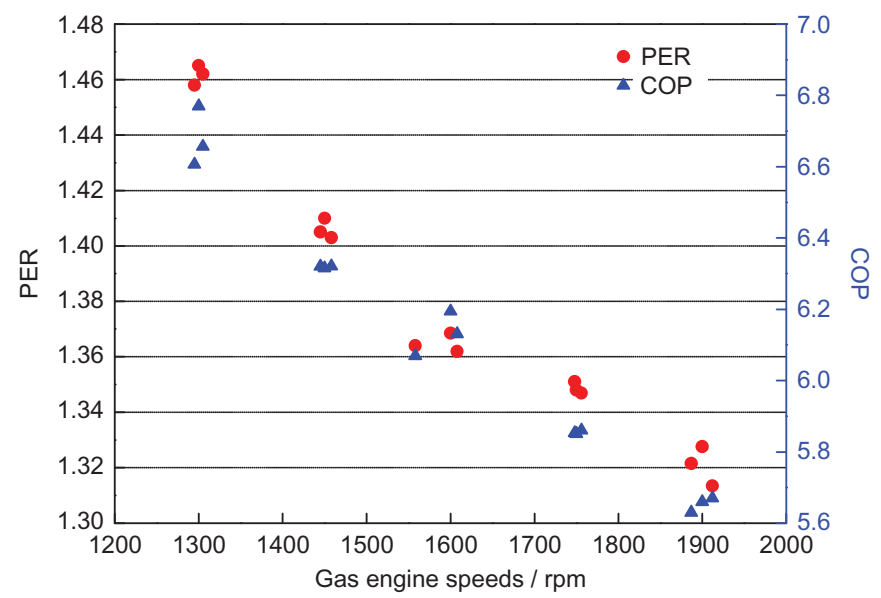

Figure 9 Variation of COP and PER versus gas engine speeds (color figure available online).

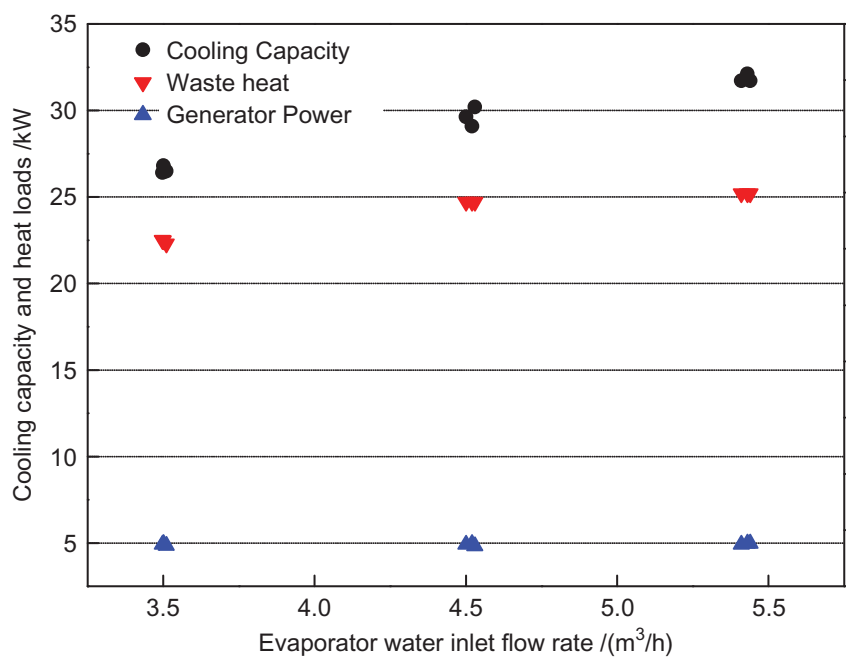

Figure 10 Variation of cooling capacity, waste heat, and generator power versus evaporator water inlet flow rate (color figure available online).

as the evaporator water inlet flow rate increases from 3.51 to $5.43 \mathrm{~m}^{3} / \mathrm{h}$, at the same time, the evaporation temperature and pressure of mixture refrigerant increase too. Therefore, the cooling capacity, waste heat, compressor power, and gas engine energy consumption will increase $19.67 \%, 13.18 \%, 8.54 \%$, and $10.1 \%$ as a result of the increasing the evaporator water inlet flow rate (Figure 11), respectively. At the same time, the generator power also remains about $4.92 \mathrm{~kW}$.

As shown in Figure 12, it is obviously that with the increase of evaporator water inlet flow rate, COP and PER are all increased with $6.2 \%$ and $6.01 \%$. The reason is that the efficiency of GEHP increases with the increase of evaporator water inlet flow rate, as a result, the performance of the whole system is improved. 


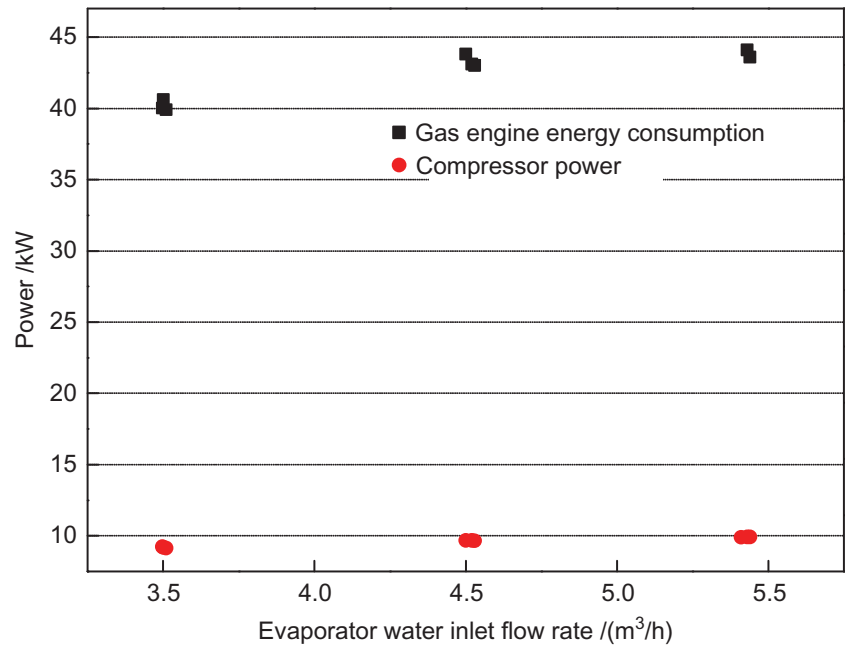

Figure 11 Variation of gas engine and system power versus evaporator water inlet flow rate (color figure available online).

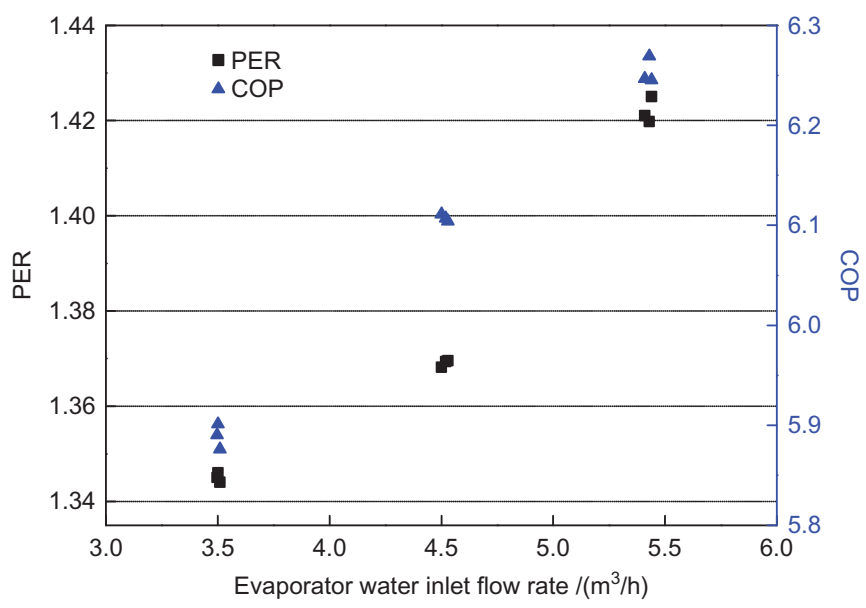

Figure 12 Variation of COP and PER versus evaporator water inlet flow rate (color figure available online).

\section{Performance of GEHP Under Different Evaporator Water Inlet Temperature}

Figure 13 represents the variation of compressor power, waste heat and generator power with the evaporator water inlet temperature under the conditions of ambient temperature $32.3^{\circ} \mathrm{C}$, gas engine speed $1300 \mathrm{rpm}$ and the evaporator water inlet flow rate $4.53 \mathrm{~m}^{3} / \mathrm{h}$. As the evaporator water inlet temperature varies from $22^{\circ} \mathrm{C}$ to $12^{\circ} \mathrm{C}$, the temperature difference between the chilled water and refrigerant will be reduced in the evaporator. Therefore, the evaporation temperature and pressure also decrease leading to decreasing of both refrigerant cooling effect and mass flow rate. The cooling capacity of GEHP decreases $17.32 \%$ as the decreasing evaporator water inlet temperature. Variations of gas engine 


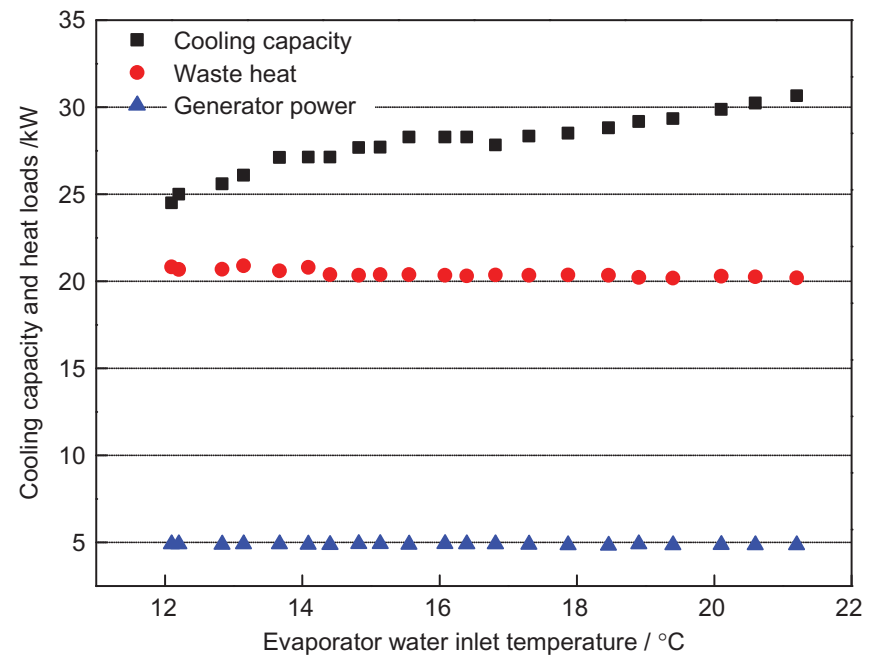

Figure 13 Variation of cooling capacity, waste heat, and generator power versus evaporator water inlet temperature (color figure available online).

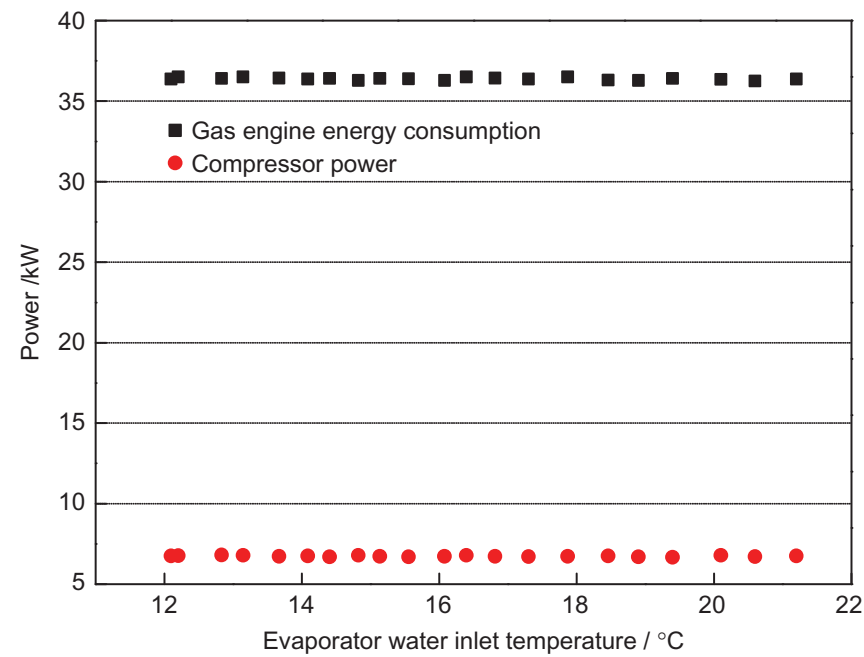

Figure 14 Variation of gas engine and system power versus evaporator water inlet temperature (color figure available online).

energy consumption and compressor power with evaporator water inlet temperature are shown in Figure 14. It is evident from this figure that the gas engine energy consumption and compressor power change in a small range, thus, waste heat and generator power also change in a small range.

The effects of evaporator water inlet temperature on the COP and PER of GEHP can be predicted from Figure 15. A higher evaporator water inlet temperature yields a higher COP and PER, it is because that a large increase in cooling capacity compared to a small change in the compressor power and gas engine energy consumption. 


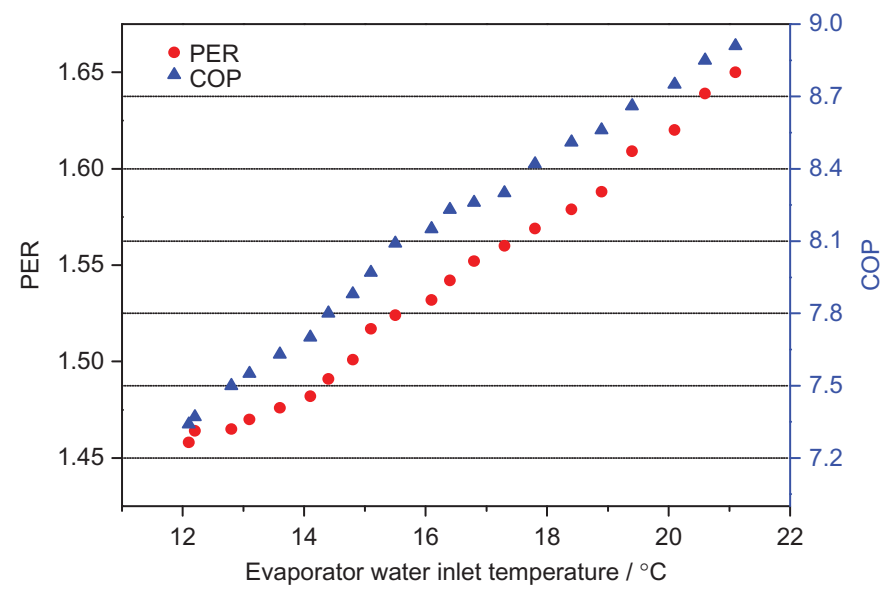

Figure 15 Variation of COP and PER versus evaporator water inlet temperature (color figure available online).

\section{CONCLUSIONS}

The operating characteristic of GEHP using mixture refrigerant R134a/R152a was investigated experimentally and presented as follows:

(1) The mixture refrigerant R134a/R152a is an alternative refrigerant with good thermodynamic, zero $O D P$ and low GWP. The proposed mixture refrigerant which explosive limits are relative small can be used safely in GEHP. The experimental results show that the mixture refrigerant R134a/R152a has better performance in the experimental GEHP system.

(2) Cooling capacity, waste heat, gas engine energy consumption, and compressor power are increased with increase of gas engine speeds and evaporator water inlet flow rate, but change in a small range with increase of evaporator water inlet temperature except the cooling capacity increasing evidently. Furthermore, the generator power generator power remains approximately $4.92 \mathrm{~kW}$ under different operating conditions.

(3) COP and PER of GEHP are also increased with the increase of evaporator water inlet flow rate and temperature, but decreased with the increase of gas engine speeds. Therefore, taking into account of the gas engine dynamic and economic property, the gas engine maintains lower speed to achieve the higher COP and PER.

(4) In the aforementioned range of operating conditions, the maximum COP and PER with mixture refrigerant R134a/R152a has been estimated with 8.88 and 1.69.

\section{ACKNOWLEDGMENTS}

This work was supported by the National Natural Science Foundation of China (Grant No. 51076112 and 51276124) and the Science and Technology Project of Tiajin City (Grant No. 12ZCDGGX49400).

\section{NOMENCLATURE}

$h \quad$ specific enthalpy $(\mathrm{kJ} / \mathrm{kg})$

$L H V \quad$ lower heating value $\left(\mathrm{kJ} / \mathrm{m}^{3}\right)$ 


$\begin{array}{ll}M & \text { mass flow rate }(\mathrm{kg} / \mathrm{s}) \\ Q & \text { heat rate }(\mathrm{kW}) \\ C_{p} & \text { specific heat }\left(\mathrm{kJ} /\left(\mathrm{kg} \cdot{ }^{\circ} \mathrm{C}\right)\right) \\ T & \text { temperature }\left({ }^{\circ} \mathrm{C}\right) \\ U & \text { voltage }(\mathrm{V}) \\ I & \text { current }(\mathrm{A}) \\ C O P & \text { coefficient of performance } \\ P E R & \text { primary energy ratio } \\ P & \text { power }(\mathrm{kW}) \\ & \\ \text { subscripts } \\ \text { exh } & \text { exhaust gas } \\ \text { cj } & \text { cylinder jacket } \\ \text { gas } & \text { natural gas } \\ e & \text { evaporator } \\ \text { com } & \text { compressor } \\ \text { all } & \text { all heat rate } \\ \text { gen } & \text { generator }\end{array}$

\section{REFERENCES}

Cabello, R., J. Navarro, and E. Torrella. 2005. Simplified steady-state modeling of a single stage vapor compression plant: Model development and validation. Applied Thermal Engineering 11-12:1740-50.

Choi, Y.M., and Y.C. Kim. 2003. Capacity modulation of an inverter-driven multi-air conditioner using electronic expansion valves. Energy 2:141-55.

Elgendy, E., and J. Schmit. 2010. Experimental study of gas engine driven air to water heat pump in cooling mode. Energy 35:2461-67.

Elgendy, E., J. Schmit, A. Khalil, and M. Fatouh. 2010. Performance of a gas engine heat pump (GEHP) using R410A for heating and cooling applications. Energy 35:4941-48.

GB/T 12474-90. 1990. Method of test for explosion limits of the combustible gases in the air, The National Standard, P.R.C. (in Chinese).

Gungor, A., Z. Erbay, and A. Hepbasli. 2011a. Exergetic analysis and evaluation of a new application of gas engine heat pumps (GEHPs) for food drying processes. Applied Energy 88:882-91.

Gungor, A., Z. Erbay, and A. Hepbasli. 2011b. Exergoeconomic analyses of a gas engine driven heat pump drier and food drying process, Applied Energy 88:2677-84.

Hepbaslia, A., Z. Erbayb, F. Icier, N. Colak, and E. Hancioglu. 2009. A review of gas engine driven heat pumps (GEHPs) for residential and industrial applications. Renewable \& Sustainable Energy Reviews 13:85-99.

Lazzarin, R., and M. Noro. 2006. District heating and gas engine heat pump: Economic analysis based on a case study. Applied Thermal Engineering 26:193-99.

Li, S.Z., W.G. Zhang, R.R. Zhang, D.X. Lv, and Z. Huang. 2005. Cascade fuzzy control for gas engine driven heat pump. Energy Conversion and Management 46:1757-66.

Li, Y.L., X.S. Zhang, and C. Liang. 2007. A novel parallel-type hybrid-power gas engine-driven heat pump system. International Journal of Refrigeration 30:1134-42.

Lian, Z.W., S.R. Park, W. Huang, Y.J. Baik, and Y. Yao. 2005. Conception of combination of gas engine-driven heat pump and water-loop heat pump system. International Journal of Refrigeration 28:810-19.

Oktay, Z. 2003. Testing of a heat-pump-assisted mechanical opener dryer. Applied Thermal Engineering 23:153-62.

Petel, J., and H.I. Henderson. 1998. Comparing gas-engine cooling system. ASHRAE Journal 3:65-69. 
Sun, Z.G. 2007. A combined heat and cold system driven by a gas industrial engine. Applied Thermal Engineering 48:366-69.

Sun, Z.G., R.Z. Wang, and W.Z. Sun. 2004. Energetic efficiency of a gas engine-driven cooling and heating system. Applied Thermal Engineering 24:941-47.

Xu, Z.J., and Z. Yang. 2009. Saving energy in the heat pump air conditioning system driven by gas engine. Energy and Buildings 41:206-11.

Yang, Z., B. Liu, and H.B. Zhao. 2004. Experimental study of the inert effect of R134a and R227ea on explosive limits of the flammable refrigerants. Experimental Thermal and Fluid Science 28:557-63.

Yang, Z., H.B. Zhao, and X.H. Li. 2005. Characteristic analysis of water heater-chiller unite driven by natural-gas engine. International Journal of Green Energy 2:79-89.

Yang, Z., H.B. Zhao, and Z. Fang. 2007. Modeling and dynamic control simulation of unitary gas engine heat pump. Energy Conversion and Management 48:3146-53.

Yang, Z., S.G. Zhang, and H.B. Zhao. 2003. Optimization study of combined refrigeration cycles driven by an engine. Applied Energy 76:379-89.

Zhang, R.R., X.S. Lu, and S.Z. Li. 2005. Analysis on the heating performance of a gas engine driven air to water pump based on a steady-style model. Energy Conversion and Management 46:1714-30. 